\title{
Chromosomal Population Analysis \\ In Cows Descendant from a Translocation Heterozygote A.I. Bull in Baviera
}

\author{
M. MENKEN \\ Aus dem Lehrstuhl für Tierzucht der Technischen Universität Munchen, \\ Freising-Weihenstephan, R.F.A.
}

\begin{abstract}
Between the many types of chromosomal aberrations, the translocations of centric fusion type are very interesting, because they result in change of the form and number of chromosomes of one given species. These aberrations were found in several domesticated animals. In domestic cattle ( $B$. taurus) there are at least four different types of centric fusions distributed among different breeds and in various countries. The most frequent centric fusion is the $1 / 29$. This aberration is found with greater frequency between the best animals used for reproduction. Wether the different types of centric fusion have a positive or negative effect on zootechnical trails is yet unclear, and so also its origin. In the present work a centric fusion of the I/29 type in a German Brown Cattle from Bavaria is described. The centric fusion was found in a very good A.I. bull, and before it was known that it was a I/29 translocation earrier his semen was used in round 30 ooo inseminations. The material studied consists in more than 4 oo cows who finished at least their first lactation. The parameters studied does not show any important deviations as expected for a normal good reproducer.
\end{abstract}

\section{Results of Orcein, C- and G-banding techniques in the Gayal (Bibos frontalis) and its crossbreds with European cattle (Bos taurus typicus)}

\author{
H. FISCHER and E. SCHEURMANN
}

Institut fur Tropische, Veterinarmedizin, Wilhelmsirasse 15, Giessen 63, R.F.A.

'The behaviour of chromosomes in crossbreds of the Gayal or Mithan (Bibos frontalis) with German Blackpied cattle (Bos taurus typicus) has been investigated in two successive crossbred generations. Bibos frontalis has a karyotype of $2 n=58$ (2 submetacentric and 54 acrocentric autosoms, $\mathrm{XX}$ and $\mathrm{XY}$ submetacentric), Bos taurus typicus karyotype is $2 n=60$ ( 58 acrocentric autosoms, $\mathrm{XX}$ and $\mathrm{XY}$ submetacentric).

$\mathrm{F}_{1}$ crossbreds have $2 n=59, \mathrm{XX}$ or $59, \mathrm{XY} .56$ autosoms are acrocentric, one unpaired autosom is submetacentric and gonosoms are submetacentric. Two $F_{1}$ females produced a calf each from German Blackpied bulls. $\mathbf{F}_{2}$ crossbred females (25 p. cent Gayal 75 p. cent Blackpied) exhibit karyotypes of $2 n=59, \mathrm{XX}$ or $2 n=60, \mathrm{XX}$. Various banding methods are used to compare banding patterns of the $F_{1}$ and $F_{2}$ crossbreds with those of the $P$ generation.

A $F_{1}$ bull from a Gayal cow and a Blackpied bull is being reared and tested andrologically.

\section{Cytogenetic Studies on Inherited Neurofibromatosis in Calves}

L. LOJDA and S. SLANINA

Veterinary Research Institute, Brno, Tchekoslovaquie

This report is concerned with the mass incidence of congenital neurofibromatosis of the skin in calves born in one area during a three-year period. The clinical picture consisted of unilateral progressive tumours on the face, and its incidence was limited to the progeny of one bull. Extensive laboratory examinations including virological examination and bioassay yielded negative results. Cytogenetic examination could be made on only 8 affected calves and 4 of the dams, 